\title{
Travma ve Multipl Skleroz
}

\author{
Trauma and Multiple Sclerosis
}

\section{Erkingül Shugaiv BİRDAY', Murat Mert ATMACA², Esme EKIZOĞLU², Murat KÜRTÜNCÜ ${ }^{2}$, Mefkûre ERAKSOY ${ }^{2}$}

\author{
${ }^{1}$ Tokat Devlet Hastanesi, TOKAT \\ ${ }^{2}$ Ístanbul Tip Fakültesi Nöroloji Ana Bilim Dall, ISTANBUL
}

\begin{abstract}
ÖZET
Multipl skleroz ve travma arasındaki ilişki yıllardır tartışılan bir konudur. Kafa ve boyun travmaları kan beyin bariyerinde değişikliğe yol açarak bazı multipl skleroz hastalarında yeni ve rekürren belirtileri tetikleyebilmektedir. Bu bildiride ağır kafa ve boyun travma öyküsü olan, bu travma sonrası multipl skleroz belirtileri gösteren, mevcut travmaları ile multipl skleroz arasındaki ilişki irdelenen olgular literatür eşliğinde tartışılacaktır.
\end{abstract}

Anahtar Kelimeler: Multipl skleroz, travma, kan-beyin bariyeri

* 28 Şubat-03 Mart 2013 tarihinde Antalya'da yapılan 6. Nöroimmunoloji Okulunda poster olarak sunulmuştur.

\section{GíRiş}

Çeşitli kafa ve boyun travmalarının multipl skleroz (MS) gelişiminde rol oynayabileceğine dair bildiriler mevcuttur (1-3). Kafa ve boyun travmaları kan beyin bariyerinde (KBB) bozulmaya yol açabilmektedir (3). KBB'deki bozulma MS lezyonlarının patogenezinde önemli bir basamaktır. Bu basamak gerçekleşmeden myelin hasarına yol açacak olan diğer olaylar meydana
The presence of a relationship between trauma and multiple sclerosis has been the subject of controversy for many years. Injuries to head or neck can cause blood-brain barrier damage and therefore may trigger new and recurrent attacks in some patients with multiple sclerosis. Patients having a history of serious head or neck trauma and developing clinical signs of multiple sclerosis after that, will be presented in this report. Furthermore, the relation between their type of trauma and multiple sclerosis will be investigated and critically evaluated reviewing the relevant literature.

Keywords: Multiple sclerosis, trauma, blood brain barrier 


\section{OLGULAR}

İstanbul Üniversitesi Tıp Fakültesi-Multipl skleroz polikliniğinden takip edilen ve ciddi travma (yüksekten düşme, trafik kazası) sonrasında atak geçiren MS hastaları tarandı. Bu tarama sonunda 3'ü erkek, 3'ü kadın olmak üzere toplam 6 hastaya ulaşıldı. Yaş ortalamas1 47.3 \pm 7.6 y1l idi (Tablo 1). Mc Donald 2005 tanı kriterlerine göre MS tanısı almış olguların öykülerinde kafa ve spinal travmaları mevcuttu. Olguların 5'inde kafa ve boyun travmasını takiben 2 gün-6 ay arasında değişen sürede MS'in ilk atağının ortaya çıktığı görüldü. Daha önce MS tanısı alan, sadece duysal atakları olan bir olguda ise travma sonrasında ağır beyinsapı-spinal atağının ortaya çıktığı izlendi. Travma sonrası ilk atağını geçiren MS hastalarının 6'ında MRG'de kraniyal lezyonlar mevcuttu ve özellikle boyun travması geçiren 3 olguda ise bunlara ek olarak servikal lezyon da görüldü. Travmalardan sonra olan atakların çoğu beyinsapıspinal atak şeklindeydi. Hastalık süresi: 16,8 $\pm 5,0$ yıl (9-24)'idi. EDSS ortalaması 3,8 $\pm 1,7$ (2,0-6,0)'idi.

Tablo 1: Travma geçiren hastaların klinik özellikleri

Yaş Cins. Travma şekli

Travma - ilk MS İlk MS atağ1 arası süre

atak şekli
MRG lezyon

dağılımı
Lomber Hastalı Son ponksiyon süresi (y) EDSS

\begin{tabular}{|c|c|c|c|c|c|c|c|c|}
\hline 59 & $\mathrm{~K}$ & kafa/boyun & 2 ay & optik nörit & $\begin{array}{l}\text { kranyal ve } \\
\text { servikal }\end{array}$ & OKB (-) & 24 & 6.0 \\
\hline 48 & $\mathrm{E}$ & boyun & 6 ay & duysal-motor & $\begin{array}{l}\text { kranyal ve } \\
\text { servikal }\end{array}$ & yok & 9 & 2.5 \\
\hline 52 & $\mathrm{E}$ & kafa & 1 ay & $\begin{array}{l}\text { beyinsap1- } \\
\text { spinal }\end{array}$ & kranyal & yok & 19 & 4.5 \\
\hline 37 & $\mathrm{~K}$ & kafa & 3 ay & beyinsap1 & kranyal & $\mathrm{OKB}(+)$ & 14 & 5.5 \\
\hline 43 & $\mathrm{E}$ & kafa/boyun & 3 ay & beyinsap1 & $\begin{array}{l}\text { kranyal ve } \\
\text { servikal }\end{array}$ & $\mathrm{OKB}(+)$ & 17 & 2.0 \\
\hline 45 & $\mathrm{~K}$ & kafa boyun & 2 gün & duysal & kranyal & yok & 18 & 2.5 \\
\hline
\end{tabular}

\section{TARTIŞMA}

SSS'ini etkileyen travmaların MS gelişimini ya da alevlenmelerini tetikleyebileceğini vurgulayan olgu düzeyinde bildiriler, küçük retrospektif kontrolsüz ve kontrollü çalışmalar bulunmaktadır $(6,7)$. Kafa ve boyun travmaları KBB'de bozulmaya yol açabilmektedir (3).

Levin ve arkadaşları kafa travması geçiren olgularda subkortikal ak madde lezyonlarının saptandığını göstermiş ve bozulmuş KBB'nin işareti olabileceğini belirtmiştir (8). Deneysel birçok çalışmalar hafif düzeyde SSS travmalarının KBB'yi değiştirdiğini göstermiştir (9-13).

Servikal spinal kord travmatik hasara daha fazla maruz kalır ve bu bölgede demiyelinizan lezyonlar sıkça görülebilmektedir. Oppenheimer MS hastalarında yaptığı otopsi sonucunda omurganın fleksiyon hareketleri sırasında dentikulat ligamanlar aracılığı ile korda iletilen mekanik stresin zamanla KBB'nin yıkılmasına ve demiyelinizasyona zemin hazırlamasına yol açabileceğini, boyun fleksiyonunun MS hastaları için tehlikeli olabileceğini belirtmiştir (14). Bizim 
çalışmamızda özellikle boyun travması geçiren 3 olguda servikal lezyon saptanmıştır.

A. Chaudhuri ve arkadaşlarının yaptığı bir çalışmada 39 MS hastasında akut servikal hiperekstansiyonhiperfleksiyon hasarının MS'in ortaya çıkmasında veya alevlenmesinde tetikleyici olabileceği ileri sürülmüştür (15). Çalışmamızda MS tanısı olan, daha önceleri hafif duysal ataklar geçirmekte olan bir olgumuzda kafaboyun travmasını takiben ağır beyinsapı-spinal atak ortaya çıkmıştır.

Travma ve MS ilişkisini inceleyen çalışmaların önemli sınırlayıcı yanları bulunmaktadır: Bu çalışmaların çoğu iyi düzenlenmiş, randomize ve kontrollü çalışmalar değildir, travmaların tipleri ve şiddetleri her çalışmada farklıdır, farklı çalışmalarda travma sonrası "riskli periyod"un süresi bir haftadan bir y1la kadar değişmektedir, hasta seçim kriterleri her çalışmada farklı ve hasta sayıları azdır (16). Bizim olgularımızda travmayı takiben 2 gün- 6 ay arasında MS belirtileri ortaya çıkmıştır.

MS ve kafa travmasının ilişkisini araştıran son yıllarda yayınlanmış İngiltere, Hollanda ve Çin kaynaklı 3 büyük, ulusal, toplum-tabanlı, prospektif çalışma bulunmaktadır. Bu çalışmalarda ulusal kayıt sistemleri kullanılmıştır. Birkaç yüz bin kafa travması olan ve olmayan, hastanelere başvurmuş hastaların MS açısından takibi yapılmıştır. $\mathrm{Bu}$ çalışmaların ikisinde kafa travması geçiren hastalarda MS gelişimi riskinin artmadığ arkadaşlarının yaptığı çalışmada ise 6 yıllık izlemde MS gelişimi riskinin arttığı gösterilmiştir (2, 17, 18). Çalışmamızdaki olguların 5'inde ilk MS ataklarının kafa ve boyun travmasından sonra ortaya çıkması dikkat çekiciydi.

Sonuç olarak küçük de olsa sunduğumuz vaka serisinde de hastaların atakları ile kafa-boyun travma arasındaki zamansal ilişki, MS’te travmanın akut alevlenme ile sonuçlanabileceğini desteklemektedir. $\mathrm{Bu}$ tür travmaların MS klinik seyrini değiştirebilir bir faktör olabileceği akılda tutulmalıdır.

\section{KAYNAKLAR}

1. Al-Afasy HH, Al-Obaidan MA, Al-Ansari YA, AlYatama SA, Al-Rukaibi MS, Makki NI, Suresh A, Akhtar S. Risk Factors for Multiple Sclerosis in Kuwait: A Population-Based Case-Control Study. Neuroepidemiology. 2013; 40 (1): 30-5.

2. Kang JH, Lin HC. Increased risk of multiple sclerosis after traumatic brain injury: a nationwide population-based study. J Neurotrauma. 2012; 29 (1); 90-5.

3. Charles M. Poster. Trauma to the Central Nervous System May Result in Formation or Enlargement of Multiple Sclerosis Plaques. Arch Neurol. 57: $1074-$ 1076

4. Compston D, Immunological aspects of MS. In: Matthews WB, ed. McAlpine's Multiple Sclerosis. $2^{\text {nd }}$ ed, New York, NY: Churchill-Livingstone Inc., 1991: 321-39.

5. Hickey WF. Migration of hematogenous cells through the blood-brain barrier and the initiation of CNS inflammation. Brain Pathol. 1991; 1(2): $97-$ 105.

6. Mc Alpine D. The problem of disseminated sclerosis. Brain. 1946; 69: 233-50.

7. Miller H. Trauma and MS. Lancet. 1964; 1: 848850.

8. Levin H, Amparo E, Eisenberg HM, Williams DH, High WM Jr, McArdle CB, Weiner RL. Magnetic resonance imaging and computerized tomography in relation to neuro-behavioral sequelae of mild and moderate head injuries. J Neurosurg. 1987; 66: 706713.

9. Ommaya A, Rockoff D, Baldwin M. Experimental cocussion: a first report. J Neurosurg. 1964; 21: 249-265.

10. Rinder L, Olsson Y. Studies on vascular permeability in experimental brain concussion. Acta Neuropathol. 1968; 11: 185-200.

11. Goodman J, Bingham W, Hunt W. Ultrastructural blood-brain barrier alteration and edema formation 
in acute spinal cord trauma. J Neurosurg. 1976; 44: 418-24.

12. Kapadia S. Ultrastructural alterations in blood vessels of the white matter after experimental cord trauma. J Neurosurg. 1984; 61: 539-44.

13. Kobrine A; Doyle T, Rizzoli H. The effect of antihistamines pn experimental psotraumatic edema of the spinal cord. Surg Neurol. 1976; 5: 307-09.

14. Oppenheimer D. The cervical cord in multiple sclerosis. Neuropathol Appl Neurobiol. 1978; 4: 151-162.

15. Chaudhuri A, Behan PO. Acute cervical hyperextension-hyperflexion injury may precipitate and/or exacerbate symptomatic multiple sclerosis. Eur J Neurol. 2001; 8 (6): 659-64.

16. Goodin DS, Ebers GC, Johnson KP, Rodriguez M, Sibley WA, Wolinsky JS. The relationship of MS to physical trauma and psychological stress: report of the Therapeutics and Technology Assessment Subcommittee of the American Academy of Neurology. Neurology; 52(9): 1737-45.

17. Goldacre MJ, Abisgold JD, Yeates DG, Seagroatt V. Risk of multiple sclerosis after head injury: record linkage study. J Neurol Neurosurg Psychiatry. 2006; 77(3): 351-3.

18. Pfleger CC, Koch-Henriksen N, Stenager E, Flachs $\mathrm{EM}$, Johansen C. Head injury is not a risk factor for multiple sclerosis: a prospective cohort study. Mult. Scler. 2009; 15(3): 294-8. 